\title{
Correction: A specific expression profile of LC3B and p62 is associated with nonresponse to neoadjuvant chemotherapy in esophageal adenocarcinomas
}

Olivia Adams, Félice A. Janser, Bastian Dislich, Sabina Berezowska, Magali Humbert, Christian A. Seiler, Dino Kröll, Julia Slotta-Huspenina, Marcus Feith, Katja Ott, Mario P. Tschan, Rupert Langer

The seventh author's name is spelled incorrectly. The correct name is: Dino Kröll.

\section{Reference}

1. Adams O, Janser FA, Dislich B, Berezowska S, Humbert M, Seiler CA, et al. (2018) A specific expression profile of LC3B and $\mathrm{p} 62$ is associated with nonresponse to neoadjuvant chemotherapy in esophageal adenocarcinomas. PLoS ONE 13(6): e0197610. https://doi.org/10.1371/journal.pone.0197610 PMID: 29897944

\section{G open access}

Citation: Adams 0, Janser FA, Dislich B, Berezowska S, Humbert M, Seiler CA, et al. (2019) Correction: A specific expression profile of LC3B and p62 is associated with nonresponse to neoadjuvant chemotherapy in esophageal adenocarcinomas. PLoS ONE 14(10): e0224832. https://doi.org/10.1371/journal.pone.0224832

Published: October 30, 2019

Copyright: @ 2019 Adams et al. This is an open access article distributed under the terms of the Creative Commons Attribution License, which permits unrestricted use, distribution, and reproduction in any medium, provided the original author and source are credited. 